\title{
Pico-Hydropower Franchising in Rural Honduras
}

\author{
Brian Thomas \\ Senior Lecturer of Electrical and Computer Engineering \\ Baylor University \\ Brian_Thomas@baylor.edu \\ Ryan McGhee \\ Graduate, Master of Engineering and Master of Business Administration \\ Baylor University \\ RyanMcGhee79@gmail.com \\ Brent Benner \\ Graduate, Bachelor of Business Administration, Finance and Entrepreneurship \\ Baylor University \\ Brent.Benner@gmail.com
}

\begin{abstract}
This paper describes a four-year effort to alleviate poverty in rural villages of Honduras by creating financially self-sustaining electricity businesses at the village level. What began as a humanitarian engineering project undertaken by students and faculty at Baylor University, subsequently evolved into a larger effort of social entrepreneurship that included the incorporation of companies in the United States and Honduras. A novel micro-franchise business model was created that used small hydropower systems to generate electricity in local villages, with local villagers having vested financial interests to maintain, distribute, and protect these systems. Two of the authors relocated to Honduras to install village-level franchises. Numerous problems plagued the project. A few months after the businesses were launched a fatal flaw was identified in the business model regarding the pace at which new systems could be deployed. Disclosure of this flaw resulted in the loss of funding. This paper will attempt to share the successes and failures of the project. Focus will be given to the most innovative aspects of our project which were largely entrepreneurial in nature. Technical details, when they are novel, will be shared, but hydro electric basics will be omitted where there is existing literature.
\end{abstract}

Index Terms - mico-franchise, pico-hydropower, rural electrification, Honduras.

\section{BACKGROUND}

Many poor villages in developing countries are located in isolated mountainous areas without access to grid-based electric power. "For those without access to electricity, lighting is derived from a diversity of sources, including kerosene, diesel, propane, biomass, candles, and yak butter." ${ }^{, i}$ In Honduras there are 7.9 million people, of which $52 \%$ live in rural environments ${ }^{\mathrm{ii}}$. A large majority of these do not have access to electricity in their homes. The predominant lighting fuel for rural Hondurans is kerosene, the burning of which can lead to respiratory disease associated with indoor air pollution ${ }^{\text {iii }}$, as well as being a significant fire hazard. Flashlights 
powered by alkaline batteries are also used and spent batteries are often improperly discarded. The state-owned electric company, Empresa Nacional de Energía Eléctrica (ENEE), is losing an estimated US\$200 million per year and, therefore, is unlikely to extend service to many of these rural customers in the near future. ENEE is unable to collect revenue for approximately $25 \%$ of the power it does generate due to three barriers ${ }^{\mathrm{iv}}$, which are also the major obstacles in bringing electricity to rural locations:

- Transmission costs; the high costs of delivery infrastructure such as large-capacity transmission lines, transformers, and substations

- Theft of electricity; the inability to prevent unauthorized connections to distribution lines

- Billing errors; the absence of a reliable billing and collection system for reaching rural households.

Over a period of four years, we identified a set of technologies and an accompanying business model to address these three problems in particular.

\section{History of Student Humanitarian Projects}

There is significant potential for even small amounts of electricity to benefit the lives of those living without it. "A well-performing energy system that improves efficient access to modern forms of energy would strengthen the opportunities for the poorest few billion people on the planet to escape the worst impacts of poverty. Such a system is also essential for meeting wider development objectives. Economic growth goes hand in hand with increased access to modern energy services, especially in low- and middle-income countries transitioning through the phase of accelerated industrial development.”v

In response to this need, travel was undertaken to Honduras in 2006 to partner with a church in the city of La Ceiba that had requested assistance bringing electricity to remote rural villages in the region. Student participants from a university organization called Engineers with a Mission $^{\text {vi }}$ at Baylor University raised their own funds to participate as volunteers between academic semesters. However, they did not receive academic credit for this work.

During two-week summer trips in 2006 and 2007, a hydroelectric generator was installed in the village Pueblo Nuevo which had about 50 homes. The generator chosen was a Vietnamesemade low head generator designed to generate $1000 \mathrm{~W}$ with $1.5 \mathrm{~m}$ of head and $130 \mathrm{l} / \mathrm{s}$ of flow (PowerPal 1000LH) and an output of $120 \mathrm{~V}$ at approximately $60 \mathrm{~Hz}$ AC. Due to a shipping error, the unit was delivered to Costa Rica instead of Honduras. The delays associated with finding the unit and trucking it to Honduras meant that the student participants were unable to perform the final installation but instead the villagers did it themselves a few weeks later with the assistance of an urban electrician hired for this task. See Figure 1. The unit provides lights to a church which also serves as community cellular phone charging station. 


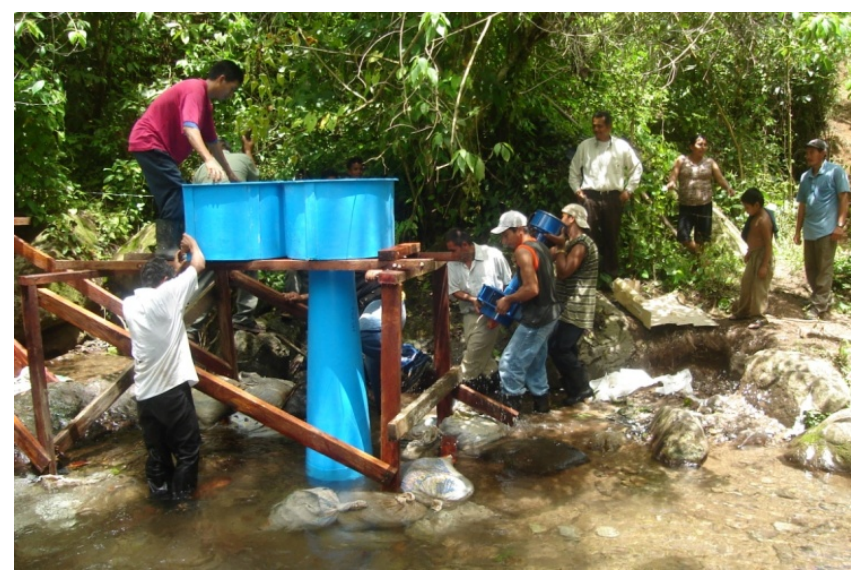

FIGURE 1

VILLAGERS IN PUEBLO NUEVO, HONDURAS INSTALL GENERATOR WITH ASSISTANCE FROM URBAN ELECTRICIAN.

\section{Problems with the Pueblo Nuevo System}

There was a degree of dissatisfaction among the villagers regarding this project. Some fluorescent lanterns were sold (below our cost) to villagers, but the batteries had to be recharged every day. This proved to be more inconvenient than it was worth, so the lanterns fell into disuse. Car batteries or deep cycle batteries were not used either despite the ability to recharge them. The villagers expressed the desire for more than battery recharging; they wanted electricity in their homes. We learned that there is a social factor involved in this desire: power lines coming to your house are a status symbol in this culture. Curiously, our initial desire was to use buried lines so that there would be less disruption of the natural beauty of the landscape, but the villagers we spoke to were not concerned with this. Ultimately, this project did not nearly satisfy the desires of the villagers. Some of these problems could have been foreseen with more thorough customer needs assessments. At this stage, our understanding of their needs was gained from informally speaking to a small number of villagers.

\section{A Sustainable Vision Grant From the NCIIA}

In late 2007 we applied for a Sustainable Vision Grant from the National Collegiate Inventors and Innovators Alliance (NCIIA). As part of the application process we were forced to more carefully consider the financial sustainability of the project and therefore created our first outline of a franchising business model as suggested by a colleague ${ }^{\text {vii }}$. We had to abandon approaching the problem strictly as engineers and began to see our efforts in a larger, developmental, entrepreneurial framework. We were successful and received a US\$50,000 grant from the NCIIA in 2008, and as part of that award were given the opportunity to attend an NCIIA Advanced Invention to Venture (AI2V) workshop to assist with the formation of our business plan. Two students attended this workshop, one of which coauthored this paper. Approximately ten weeks of follow-on coaching was provided by the NCIIA with entrepreneur Mary Howard ${ }^{\text {viii }}$ regarding the development of fund-raising strategies and further refinement of 
our business plan. These tools proved to be extremely helpful to our project in that they taught us to think more like entrepreneurs and not solely engineers.

This NCIIA grant enabled travel to Honduras for seven weeks during the summer of 2008 when a new system was built in a village called Danta Uno. See Figure 2. This system also used hydropower as the energy source and employed a Canadian-made $48 \mathrm{~V}$ DC generator to charge a bank of lead acid batteries. An abandoned concrete dam, once used for drinking water collection, was used to establish the required head. The generator produced a maximum of about $800 \mathrm{~W}$ with $2 \mathrm{~m}$ of head and $63 \mathrm{l} / \mathrm{s}$ of flow, and ran 24 hours/day. A $3000 \mathrm{~W}$ inverter was used to deliver power during the peak times of 6:00 PM-9:00 PM. The inverter fed a distribution network that reached most of the homes in the village. In all, 23 homes, a school, and a church received power. A metering system was put in place at each home along with a $1 \mathrm{~A}$ fuse for safety and power limiting. This system relied heavily on two excellent sources: Harvey's MicroHydro Design Manual ${ }^{\mathrm{ix}}$ and Inversin’s Micro-Hydropower Sourcebook ${ }^{\mathrm{x}}$.

The meters were programmed to charge the equivalent of US\$1.07 per kilowatt hour, which is what our initial business plan called for. While this is a much higher rate than electricity delivered by the US or Honduran grids, it is actually a great improvement over their existing light sources in terms of useful energy per dollar. A $15 \mathrm{~W}$ compact fluorescent light in this system produces over 25 times as much light per dollar (lux/US\$) as a kerosene-burning lantern, or over 115 times as much light per dollar as a hand-held flashlight used with disposable alkaline batteries. ${ }^{\mathrm{xi}}$

Following the example of the micro-finance industry to use social pressures to ensure loan repayments ${ }^{\mathrm{xii}}$, three families in the village were identified through an application and interview process. These families agreed to work on the various tasks of the business in exchange for a monthly salary. Although we did not tell them at that time, our plan was that these three families would transition into partially owning the franchise. The details of this are discussed under the heading Business Plan Details. It should be noted, however, that all of the interviewees expressed a desire to help their community receive access to electricity as one of the main reasons they wanted the job.

\section{Problems with the Danta Uno System}

The complete system began generating power, paying its employees, and collecting revenue in August of 2008, but was damaged by a lightning strike and subsequent flood by November 2008. The lightning strike damaged the inverter and the flood was severe enough to rip out all the PVC pipe used to channel water to the generator. There was also considerable difficulty in communications at this time. The three families in the village did not contact the urban electrician who we chose to be a liaison between us (now back in the United States) and them. No villager input was sought regarding the choice of electrician, but we witnessed what appeared to be an amiable relationship between the parties during the installation of the electric lines. Two or three months passed before we were informed, despite excellent cellular telephone coverage. We still do not completely understand this delay, but our best understanding is that there was a cultural misunderstanding involved in the decision not to call us. From their perspective, to call us may have been seen as a presumptuous complaint or a rude demand, while from our perspective, we viewed the decision not to call as irresponsible and negligent. Even after subsequent conversations, we have not been able to fully overcome this difficulty, and the reporting of problems is slow. 


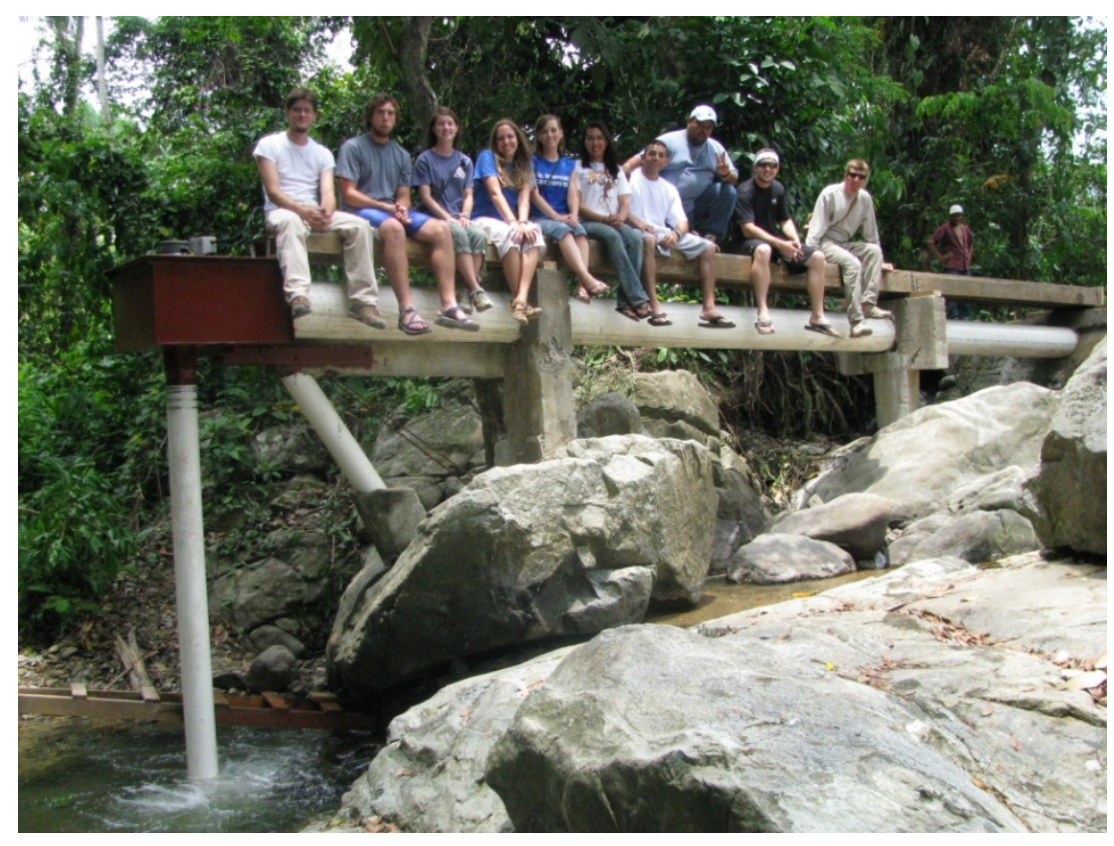

FIGURE 2

STUDENT TEAM DESIGNS AND INSTALLS HYDROPOWER SYSTEM IN DANTA UNO, HONDURAS.

The 1 A fuses we installed in each home also were problematic. The villagers frequently blew fuses so the three families that were our employees "solved" the problem by bypassing them with wires. They showed us with a measure of pride how they had made this "improvement" without the need to consult us.

The meters also proved to be problematic. A few of them were damaged, perhaps from the lightning strike, and several villagers argued about their bills, claiming the meters were giving wrong results. Some explained how their child had left the light on and made their bill higher than expected and argued that they should not have to pay the full amount in such a case.

During the next two-week trip in May 2009 the damages were repaired. Extra lightning arrestors and circuit breakers were installed and new PVC pipes were installed in a substantially more robust, concrete mounting structure. See Figure 2. Upstream of the dam, concrete structures and rock-filled wire cages (gabions) were built to deflect debris rushing downstream during floods. Debris as large as tree trunks and boulders are expected in future floods. The meters and fuses were replaced with a novel circuit breaker device and a completely different type of billing, discussed under the heading Our Solution.

\section{FORMATION OF COMPANIES}

For-Profit vs. Non-Profit

The primary purpose underlying all our efforts to bring electricity to rural homes was to help people. In that light, the decision to form a for-profit vs. a non-profit company was debated and legal counsel was sought in the United States. We agreed that despite a non-profit's ability to 
raise donations quickly, a for-profit model was preferable. In the long term, a for-profit model would allow investments that we supposed would be larger than the donations we would receive as a non-profit, and therefore we would be able to help more people. Our goal was to increase the economic self-reliance of villagers, so the micro-franchise model illustrated in Figure 3 was chosen. Figure 3 is adapted from the book by Fairbourne, Gibson, and Dyer called Microfranchising. ${ }^{\text {xiii }}$

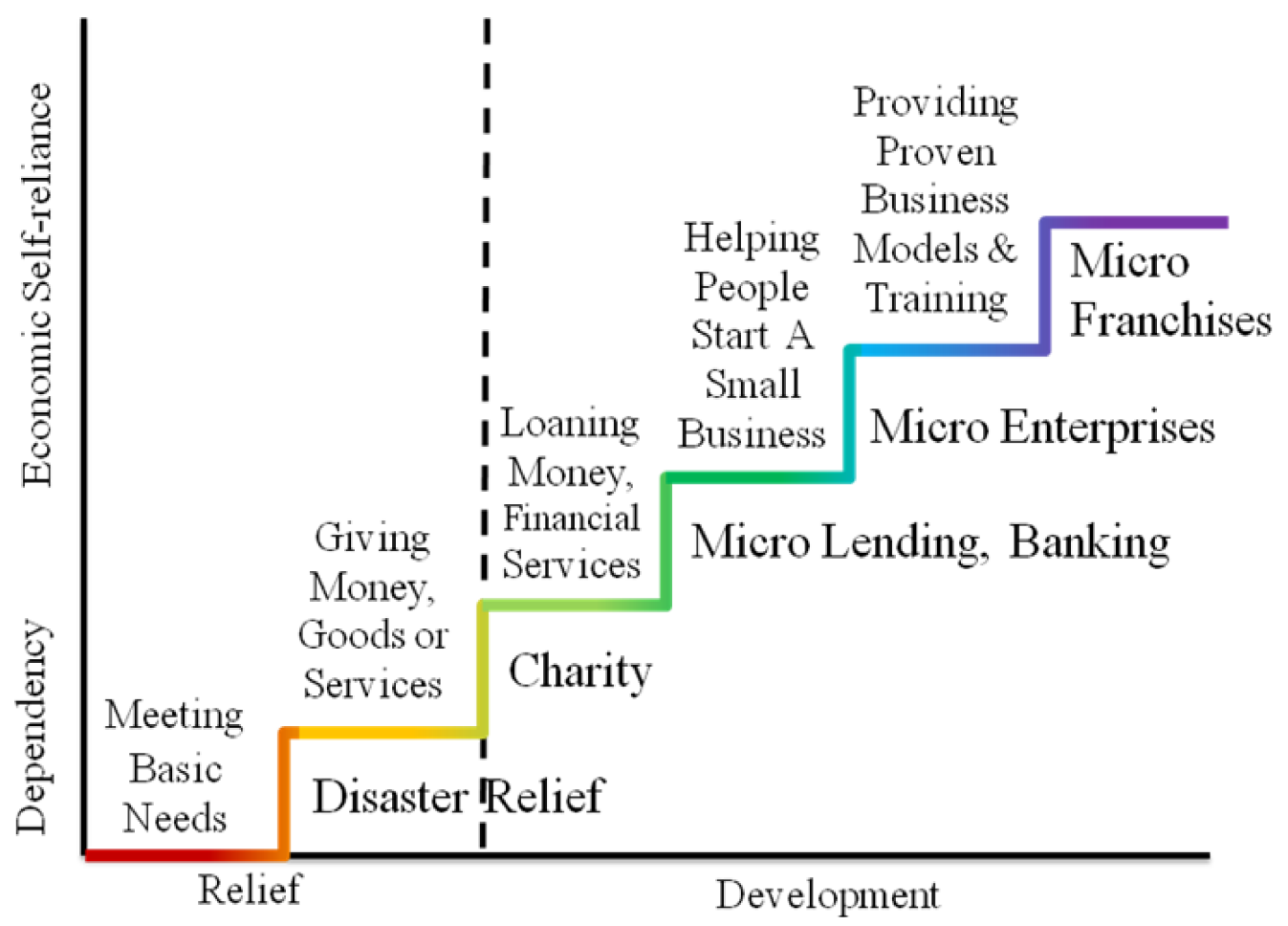

FIGURE 3

MICROFRANCHISING WAS CHOSEN TO PROMOTE ECONOMIC SELF-RELIANCE.

This greater access to capital, we thought, would allow us to help more people faster, and so we chose to incorporate as a for-profit organization. A second factor that influenced our decision to incorporate as a for-profit were the ease and speed of doing this, both in the United States and Honduras, compared to incorporating and registering a non-profit. Furthermore, from our own observations and the counsel of those with experience working in Honduras, we were aware of a cultural tendency on the part of some Hondurans to expect non-profit organizations to act more like charities. We wanted each village franchise to operate as a financially self-sustaining organization, not a charity giving away electricity, and therefore wanted to set the example of this at the corporate, or franchiser, level. In January 2010, Village Energy LLC was incorporated in the state of Texas to be our primary business entity. Our long range plan was to have similar operations in other countries, each with their own national business entity which would be majority owned by Village Energy. Our plan was that the first of these national entities would be located in Honduras and be called Energía Para Aldeas, which means energy for villages in Spanish. It would quickly be incorporated in Honduras and be $98 \%$ owned by Village Energy. The other $2 \%$ was to be owned by individuals, as is required by Honduran law. (The 
incorporation of EPA began in February 2010 but it was not finalized for many months.) We consider Village Energy LLC a triple-bottom-line company meaning we value not only profit, but people and the planet. This is not a legal status but rather a statement of corporate values. Social, financial, and environmental gains, in that order, are each evaluated as bottom lines themselves. These decisions were influenced by Polak's book "Out of Poverty"xiv and "Electricity Services in Remote Rural Communities, The Small Enterprise Model” by Sanchez. ${ }^{\mathrm{xv}}$

\section{Business Plan Details}

In order to achieve financial viability, our Honduran business entity, EPA, needed to obtain economies of scale quickly. In the business plan, a separate franchise is formed for each village, but is majority owned by EPA. Within each village, three local individuals or families maintain an ownership percentage comprising $30 \%$ total. Two employees are hired to do perform daily duties such as the collection of monthly bills as well as performing regular maintenance checks or even disconnecting nonpaying customers. They earn a vested percentage over a five year timeline in addition to a labor wage during the vesting period. A third shareowner leases the land to EPA on which the power generating equipment is housed. This shareowner receives his/her ownership percentage immediately.

This method of vesting employees over time is known as the BOOT Model ${ }^{\text {xvi }}$ of microfranchising. BOOT is an acronym that stands for Build, Own, Operate, and then gradually Transfer ownership. EPA would provide the capital and/or secure low interest loans for the equipment, design the system, own it and operate it through employees which eventually vest into partial ownership and share profits. The five year vesting period corresponds to the time required to repay the initial loans.

Figure 4 illustrates the flow of money and services. During our first year, the goal was to install 12 systems, or one per month. The five year goal was 144 systems. Eventually, the goal was to have installed enough hydropower to sell carbon credits as an additional income stream. However, it would take a few years to deploy enough systems to make it worth the expense.

\section{Is Demand Sufficient?}

Demand consists not only of the desire for a product or service but also the ability and willingness to pay for that service at levels that are profitable for the business meeting that demand. Villagers desired electricity, but their ability and willingness to support a business was in question. We performed surveys of several villages in the region and found that the average household income is US\$91 per month. For the villagers, the purchase of kerosene and batteries is not convenient while the recharging of cellular telephones requires traveling to other towns or cities and often involves recharging fees. We conducted surveys that showed the average family of 4.5 people spends $\$ 7.06$ monthly on these expenses. Our entry-level pricing point was chosen, therefore, so that customers can simply reallocate their current expenditures for kerosene, flashlight batteries, and cellular phone charging, towards the purchase of electricity. See Table I. Furthermore, we believed many of our customers would be willing to pay more than this because of the superior quality of electric light, the added convenience of home delivery, and the perceived improvement in social status among those with electricity. For more details regarding the survey, please see Appendix A. 


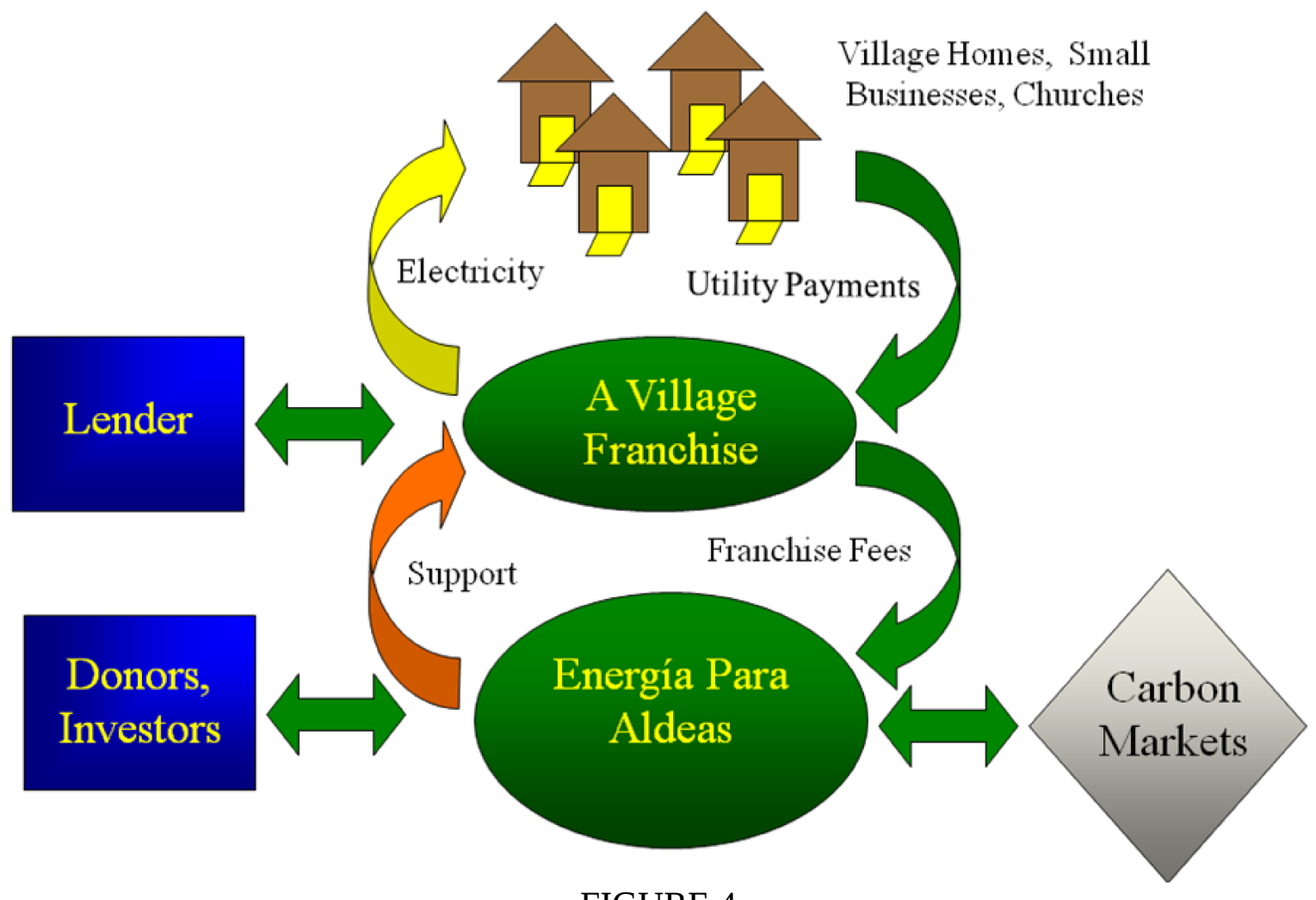

FIGURE 4

FLOW OF MONEY AND SERVICES IN BUSINESS PLAN.

\section{Our Solution to the Three Barriers}

Our business plan overcame the three barriers described above that make it financially prohibitive to serve a low-density population with centralized electricity production. These solutions are:

1) Avoidance of the high costs of delivery infrastructure such as large-capacity power lines, transformers, and substations, by generating relatively small amounts of power locally (1-10 $\mathrm{kW}$ ), in the village, using the hydropower of small mountain streams. Local power generation means shorter distribution lines of very small capacity which drastically reduces their costs. Our distribution network operates at $120 \mathrm{~V}$ AC (no transformers) on insulated aluminum triplex cable (such as connects most houses to the grid in the United States) and common circuit breakers. The distribution network is held above ground by carefully mounting the lines to trees. In particular, a tree that the villagers call the madreado tree, grows long straight braches which quickly take root when cut off and planted in the ground. See Figure 5. In fact, many village farmers use them for erecting barbed wire fences. In this sense they are culturally appropriate and environmentally benign compared to traditional, chemically treated, expensive, power poles. While there is increased maintenance required by using living trees as power poles, the smaller scale and everyday presence of the employees makes such maintenance practical. The maintenance of the generation equipment and distribution lines is performed by local individuals and on a part-time basis. Business, technical, and safety training would be provided to these individuals during installation and on an ongoing basis. 
2) A tiered subscription-based fee system, instead of a metered system, greatly simplifies the accounting and collections functions. Rural households bring their monthly payments to a local operator, so the absence of a reliable postal system does not affect collections. Furthermore, disconnection for non-payment is simpler and less expensive since the operator does not have to travel far to the user's location; he or she can simply walk.

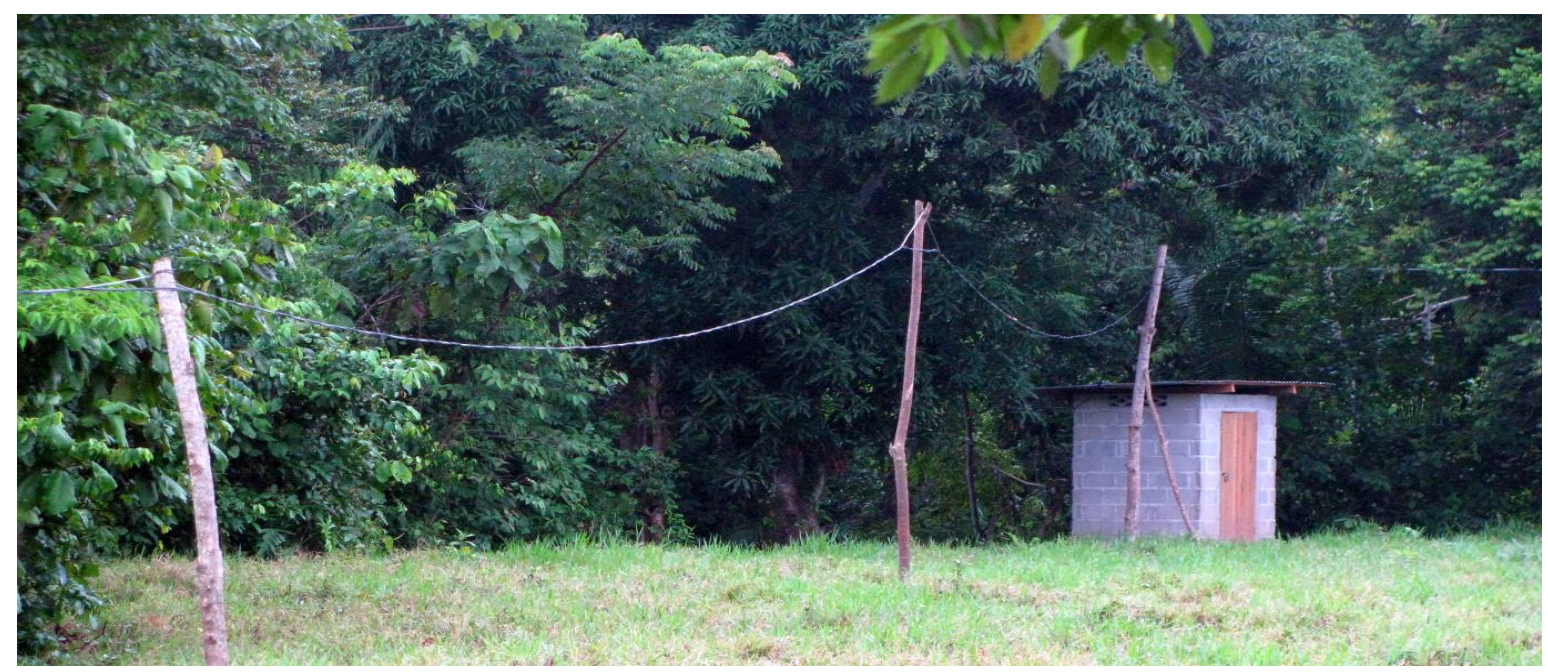

FIGURE 5

MADREADO TREES FRESHLY CUT AND USED AS POWER POLES.

Several pricing/power tiers are available. For example: providing just enough power to operate a $25 \mathrm{~W}$ compact fluorescent light, to providing sufficient power to operate a refrigerator and television. See Table I. Each pricing/power tier corresponds to the maximum amount of power a household can use. Unlike meters that measure energy, our systems use a limiter to limit the maximum power a household can receive at any given time. Payment, therefore, is for access to capped levels of power (in Watts) not energy (in Watt-hours). Each limiter is, essentially, an electronically resetting circuit breaker. If the household exceeds their current (and hence power) rating, the circuit breaker will open for 15 seconds, interrupting the electricity being delivered to the house. The delay allows the customers to reduce their consumption by unplugging an appliance. If they do not, the breaker will continue to cycle off for 15 seconds until the current drops below the limit. Figure 6 shows two village employees installing a limiter at a home. The limiters were designed for exactly this purpose by Sustainable Control Systems in the UK.

TABLE I

PRICING/POWER TIERS

\begin{tabular}{cc}
\hline Current Limit (A) & Monthly Rate (US\$) \\
\hline 0.25 & 6.62 \\
0.5 & 7.94 \\
1.0 & 10.58 \\
2.5 & 18.52 \\
\hline
\end{tabular}


EPA chose to utilize a subscription model instead of a traditional meter because it is also culturally more appropriate. Our target customers have problems budgeting their finances and are usually unaware how much they actually spend on energy use in any given month. The customers do not have to worry about accidentally leaving a light on or the family using too much electricity because they will be paying the same amount each month regardless of total usage. This allows the families to budget for the cost of electricity. This model is also used for water delivery. Each home has a single spigot from which they may receive water. Meters are not used, but a flat monthly fee is charged per household. However, there are two major differences between their water system and our electric systems: the costs of the water system are subsidized by the government, and non-payment of the fee will not result in disconnection of water services. There is a measure of social pressure to pay the monthly water fee, but not paying it does not result in the loss of service.

3) Theft of electricity in Honduras is typically accomplished by making unauthorized connections to power distribution lines. This theft is thwarted not only by the presence of the operator on a daily basis, but by the operator's financial stake in the franchise via partial ownership. Partial ownership personally motivates the operator to prevent the theft of his own property.

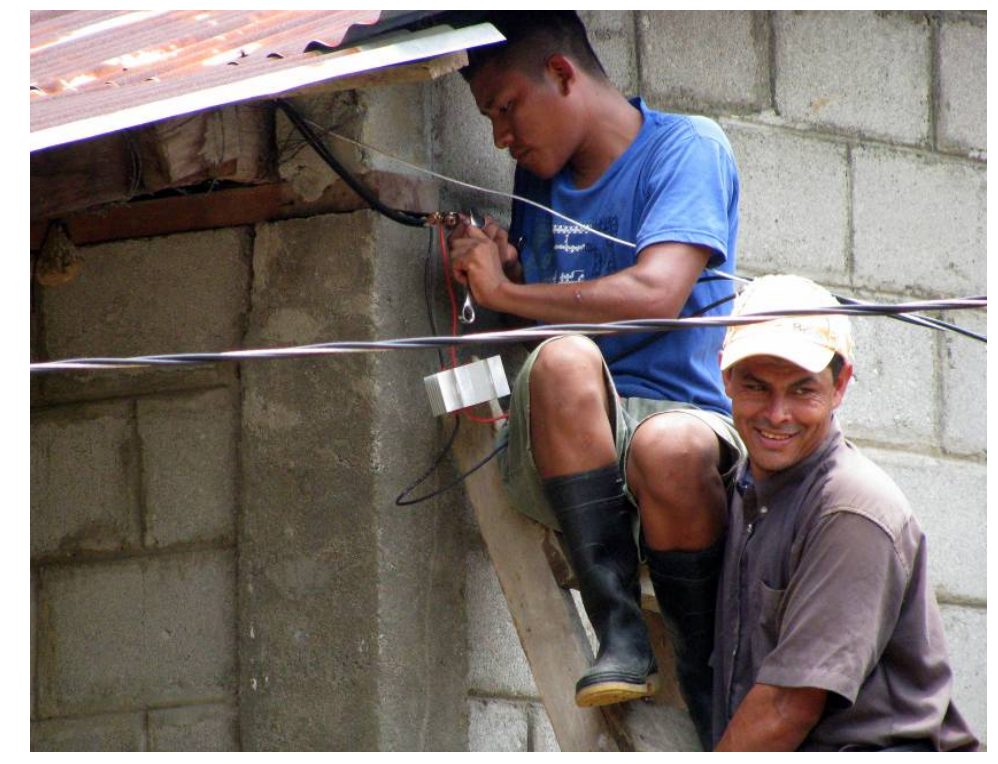

FIGURE 6

VILLAGE EMPLOYEES INSTALLING A LIMITER AT A HOME.

\section{Technical Details}

Although our first two systems in Pueblo Nuevo and Danta Uno used permanent magnet generators, they are not easily repairable in Honduras. However, common electric motors known as induction motors can be used as generators when their rotors turn faster than the synchronous speed. ${ }^{\text {xvii }}$ In order to reduce costs and improve the ability to locally repair the generators, we 
planned to abandon permanent magnet generators for induction motors used as generators and use a commercially available induction motor controller.

The power is transmitted from the generating location to the village on a standard triplex cable consisting of two insulated and one bear aluminum cable. Unlike most power distribution systems that use tall poles and bare metal lines, the insulated conductors not only increase the safety, but also make it much more difficult for people to steal power as they cannot throw a bare wire over the electric lines to make a quick connection.

\section{Strategic Partnerships}

During the fall of 2009, the project received the Energy Innovation Contest grant for US\$200,000 from the Inter-American Development Bank and Global Village Energy Partnership. Our partner for the grant is the Asociación Hondureña de Pequeños Productores de Energía Renovable (AHPPER) which means the Honduran Association of Small Renewable Energy Producers. They provided legal advice concerning incorporation and environmental permitting. The grant was payable over eight quarterly installments and came with two limitations that caused us considerable trouble. The first was that the grant could not be used to pay salaries of foreign nationals. The second limitation was that the grant could not be used to purchase a vehicle despite our need for a four-wheel-drive truck to access remote villages on difficult roads. A request for an exception to this limitation was made but denied. This required additional fund raising in the form of gifts from private individuals supportive of our cause.

\section{DEPLOYMENT IN HONDURAS}

In February 2010, two of the authors moved to La Ceiba, Honduras to begin operations. Their first tasks included working with AHPPER to get EPA legally incorporated and to determine the locations of the next village franchises.

\section{Determination of Village Suitability}

In order to determine the suitability of the village for the implementation of a franchise, a socioeconomic survey was conducted (see Appendix A). The aim of this survey was to gauge the village's ability to afford paying for electricity. The survey was conducted from house to house and primarily consisted of questions relating to average monthly energy expenses and approximate monthly income. Once at least $80 \%$ of the village's households had been surveyed, the results were compiled and analyzed. We attempted to use the results to determine the profitability of installing a system in any individual village. If a village passed this initial test of potential profitability, we continued with the steps towards implementation.

An analysis of the hydro resource was performed and a preferred generator location was chosen. Additional surveying was done with a Global Positioning System (GPS) receiver to record the location of each home in a village. These coordinates were entered into the publicdomain software application Google ${ }^{\mathrm{TM}}$ Earth to create a village map. This map was used to design the distribution network and to decide which homes were close enough to the hydro generator to be economically serviceable. See Figure 7. 


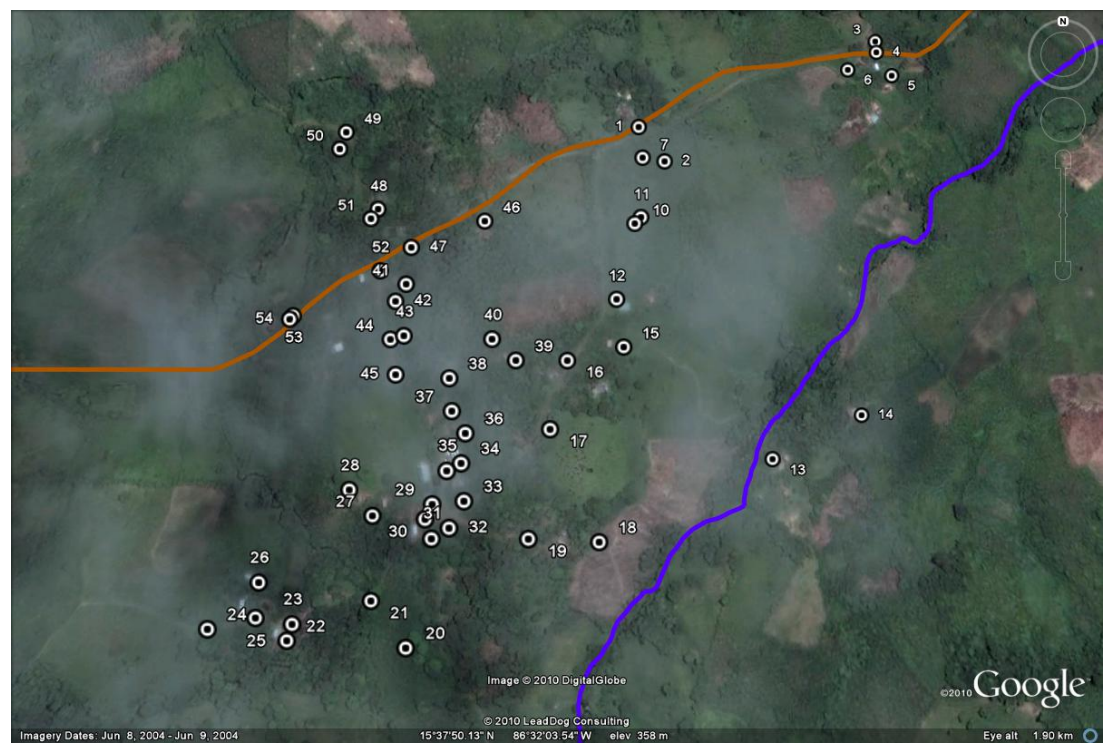

FIGURE 7

VILLAGE MAP USING GPS RECEIVER AND GOOGLE ${ }^{\text {TM }}$ EARTH, WITH ROAD AND RIVER HIGHLIGHTED.

\section{Difficulties with Culture}

Several difficulties were encountered that can be attributed to cultural obstacles. It must be noted that we were extremely aware that there would be obstacles. The hardest obstacle was the widely-held belief that private business is bad. Most communities were considerably opposed to the idea of a private company distributing electricity in their village. They objected to the idea of someone making a profit by selling electricity. Community members preferred that the systems be built by EPA and then ownership be turned over to the community immediately or at least once the initial capital had been recuperated. In an effort to engage the community in a dialog, we asked the patrónatos (community leaders) of the villages to convene town meetings at village schools or churches. These meetings were attended by many of the adults in the community and during them we presented our ideas of bringing an electricity franchise to their village. We engaged in numerous debates during these meetings attempting to explain why we were a forprofit company. Tendencies toward socialism are so ingrained within the culture that there was strong and vocal backlash towards a private for-profit enterprise. We also encountered difficulty dealing with university-educated municipal leaders in the cities that govern the region which contained villages we targeted. These leaders were afraid we would be taking advantage of the communities even though we assured them we were trying to serve them by providing a valuable service. It is understandable that such leaders are apprehensive because numerous private hydropower companies have built larger projects (multi-megawatt) that do not provide power to the nearby communities from which their energy source is derived. Instead, their focus is to generate profits by selling energy to the national grid. The communities in the immediate area do not receive the benefit of electricity yet are adversely affected because at times these projects have negative environmental consequences. Without the approval of municipal leaders, it was extremely difficult to move individual villages through the necessary process for 
implementation. To overcome this difficulty required villagers travel to the cities to meet with their municipal leaders and request one of our franchises in person. When their constituents, instead of expatriates, requested our services they were much more willing to accommodate.

We also encountered problems by not providing electrical service to $100 \%$ of the homes in a village. If a group of homes were not economically serviceable as determined from our maps and analysis, then they would not receive electricity. However, there was considerable community backlash to the idea of less than 100\% coverage. Their argument of "We are all part of this community, so we should all get electricity" reminded us that they did not perceive private enterprise (or the mathematics behind the economics) in the same way we did. Some communities went so far as to refuse service altogether if the coverage could not be $100 \%$. In our view, those households that did not receive electricity were no worse off than they were before and to deny some electricity because others could not have it seemed selfish and shortsighted. However, we undervalued the importance of community in this culture. If an incomplete access to electricity exists, then a growing division could arise between those that have it and those that do not. This could lead to tension and threaten the unity of the community. In a community without police or emergency response services, one's neighbor is, perhaps, more important to one's very survival than in our own urban culture.

Furthermore, most agriculturalists in Honduras work five hours per day. It was very difficult to motivate the day laborers to work more than this; they either demanded as much as a 50\% pay premium to work a full eight hours per day or simply refused to work more than five hours per day regardless. This made it difficult to maintain construction schedules and complete deadlines.

Lastly, countries that were at one time Spanish colonies often continue to suffer from a "hacienda mentality." Haciendas first appeared in the sixteenth century and were large estates or plantations, owned by an elite group (the patrón) and employing large numbers of peasants (the peones). There was a symbiotic relationship between the patrón and the peones; the peones labored for the patrón and in exchange received food, shelter, and other basic needs. But in today's culture, the role of the patrón is filled by the national and/or municipal government. There is a common perspective that the government can and should meet the needs (such as electricity) of its people. Past NGOs and other development workers contributed to this mindset. A few NGOs and at least one government funded agency built systems similar to those of EPA and then donated or handed over control to the community. One village who had such a system contacted EPA and asked us to fix their broken system. The system was broken because the community decided to reduce the monthly consumption fee and thus didn't have the funds to maintain the system properly. They also didn't have any way of paying for the system to be repaired or a plan to raise the necessary funds. Since the community mismanaged the project and did not collect sufficient funds, no one had electricity. Despite examples like this one, communities still insisted that private companies should not be allowed to provide electrification for a profit.

\section{Legal Confusion}

EPA received conflicting legal advice on several occasions. Our partner AHPPER has attorneys in its membership who gave us legal advice. Before relocating to Honduras and again during the first few months there, we were advised that the system size we would be deploying was small enough ( $<3 \mathrm{MW}$ ) that we would not have to undergo the approval process by SERNA, the 
Honduran version of the Environmental Protection Agency in the United States. Since the SERNA approval process takes seven or eight months on average, it was imperative that we not have to undergo such a process. If approval was required, we could not legally commence construction until the end of that process. This would have made operations impossible because EPA was attempting to deploy at least 12 projects per year. Later, a different attorney with ties to AHPPER informed us that it would, indeed, be necessary to get SERNA's approval.

SERNA itself provided contradicting advice as well. During our initial meeting with them we were informed we would not require SERNA's approval for each project because each system was smaller than the threshold needed for approval. Several months later, a different SERNA employee with a higher rank, advised us otherwise. In conclusion, it is probable that SERNA's approval is needed for hydro projects of any size.

\section{Funding Problems}

In December 2009 and January 2010, we received promises of US\$40,000 that we could use towards the expenses that the Energy Innovation Contest grant would not cover. However, an additional US\$60,000 was required to purchase a suitable vehicle and pay expatriate salaries for two of the authors for the remainder of the first year. The third author (Thomas) was involved in the business from the United States, while attempting further fundraising. However, raising more money in the form of gifts proved difficult because the for-profit status prevented donors from receiving tax deductions for their gifts. This meant that the authors were only paid for three months, despite working in Honduras for seven months before being forced to return to the United States. Their pay was modest: US\$2,900 per month. While working, they were also forced to use public transportation and frequently hike into villages on foot, because a vehicle could not be purchased. This exacerbated the delays we were experiencing due to labor problems and legal issues. Our repeated request to use grant funds to purchase a vehicle were denied.

In retrospect, we should have been more communicative with the granting agency before accepting the first quarter's distribution, an act which began the two-year timeline. We should have explored pushing back the project start date until the additional funding had been secured. However, we felt a measure of pressure from GVEP to begin immediately, and gambled that we would indeed be able to raise the additional US\$60,000 in the coming months.

Furthermore, Baylor University, itself a non-profit organization, required us to put formal distance between the company and the operations of the university since one of the authors was on the faculty there. This meant, importantly, that university students could no longer volunteer to work on these projects, because the university legal counsel feared the appearance of private inurnment, which could threaten the non-profit status of the university. This obstacles was not foreseen and, therefore, caused us considerable difficulty.

\section{Custom-Designed Civil Structures Take Too Long}

It was anticipated that civil works (such as dams and canals) would have to be designed for each location, but we had hoped that after designing and constructing several systems we would be able to quickly modify old designs to new locations. Delegation to local labor proved too difficult and it seemed that having an engineer on site for the duration of each project was going to be a requirement. This drove our costs up and made our deployment times unacceptably long. 


\section{Collapse of Energía Para Aldeas}

The authors were forced to leave the Honduran operations in July 2010. At this point they had been working for four months without pay. We informed GVEP of our difficulties in our second quarterly report, and told them that we no longer considered our original business plan to be feasible, primarily because it called for rapid deployment of large numbers of systems. Furthermore, the deployment of pico-hydro power systems did not lend itself to scalability or an easily franchisable model under Honduran law. Therefore, EPA requested the opportunity to submit a new business plan based on a different technology utilizing either a battery distribution model or the use of single-lamp solar panels. However, GVEP rejected this proposal and the grant was terminated.

\section{Lessons Learned}

One of our assumptions from the very beginning was that hydro power is, generally speaking, less expensive than other forms of energy (solar, wind, diesel generators) in terms of dollars per watt (US\$/W). While this is true when considering equipment costs and even the engineering costs associated with a single project, or when engineering time is volunteered, we have concluded that this is not true for deploying large numbers of similar, but not identical, systems. The custom engineering required, and the extremely difficult working conditions and legal and environmental confusion, represent hidden costs that make pico-hydro less cost effective.

We were told by one of the larger hydro development companies working in Honduras that they where no longer going to be pursuing medium sized systems and instead were going to focus on projects in the $100 \mathrm{MW}$ range. They had found that the amount of work and time required to design and build a small 2 MW system and that required for a $100 \mathrm{MW}$ system was almost identical for these reasons.

We strongly conclude that in Honduras, small, personally-owned solar photovoltaic systems with white LED lamps are a better option for rural families without electricity. These are already commercially available and two such systems that show much promise are products by d.light ${ }^{\mathrm{TM}}$ and the Ulitium products by Sundaya. These systems are far more rapidly scalable to large numbers of people, because the same product works identically at each home. There are no distribution lines to plan or civil works to design, and therefore this technology lends itself to a franchise business plan much more readily. However, the relatively high initial costs to the user will likely require some novel financial mechanisms to enable impoverished people to afford them.

\section{The Future of EPA and Village Energy LLC}

Our conclusion that using small solar photovoltaics with white LED lights is more culturally appropriate is so strong that we considered reforming our company into a distributor of these products. However, we found that there are already well-established business entities in Honduras that have reached the same conclusion and are pursuing the same direction. Since we seem to have no competitive advantage over these entities, however, we have decided not to do this. Instead, at the time of this writing we are considering building private grids, similar to those in our franchises, but while partnering with larger hydro developers building multi 
megawatt systems. One of the developers of these systems intends to sell energy to the national grid and to use the funds for socially constructive development projects.

\section{APPENDIX A: SOCIOECONOMIC SURVEY}

The socioeconomic survey was used to determine the ability of a particular village to pay for electricity services. It produced the following compiled results. We spoke to 130 households in the region; the average household consists of 5.58 people total, comprised of 3.00 school children and 2.53 adults. The approximate monthly income was US $\$ 90.69 /$ month. Households on average spent approximately US\$7.06 per month on costs related to energy expenses. These include purchasing approximately 3.72 liters of kerosene for US\$3.25, purchasing 2.34 pairs of batteries for US\$2.09, and recharging their cell phone every 4.79 days for a total monthly cost of $\$ 1.50$. The exchange rate used was US $\$ 1=\mathrm{L}$. 18.895. The questions have been translated from Spanish to English by the authors.

1) Record GPS location of house.

2) Who is the head of the household?

3) How many people currently live in this dwelling?

a. How many are school children?

b. How many are adults?

4) What is the occupation of the head of household?

a. Spouse occupation?

5) What is your approximate monthly income?

a. During the harvest season?

b. Non-farming months?

6) How often do you buy kerosene?

a. How much does a liter cost?

b. Where do you buy kerosene?

7) How often do you buy batteries for your flashlight and radio?

a. How much does each pair cost? 
b. Where do you buy them?

8) How often do you recharge your cell phone?

a. How much do you pay for this service?

b. Where do recharge the cell phone? How far away?

9) How much cooking wood do you use per week?

10) How much do you spend monthly for water service?

a. Do you pay on time?

b. Do you think the majority of the population pays their bill on time?

i. Approximately, what percentage?

11) If you had access to electricity, are there any ways you could earn additional income?

a. What type of business or activity?

APPENDIX B: VARIATION BY VILLAGE OF SOCIOECONOMIC DATA

\begin{tabular}{|l|c|c|c|}
\hline \multicolumn{4}{|c|}{ Kerosene } \\
\hline \multicolumn{1}{|c|}{ Village } & Liters/Month & L./mo. & US\$/mo. \\
\hline Danta Uno & 3.4 & 57.8 & 3.06 \\
\hline Nuevo Jutiapa & 4.16 & 66.0 & 3.49 \\
\hline Las Flores & 3.59 & 61.0 & 3.23 \\
\hline La Paz & 3.71 & 61.0 & 3.23 \\
\hline All & 3.72 & 61.5 & 3.25 \\
\hline
\end{tabular}

\begin{tabular}{|l|c|c|c|}
\hline \multicolumn{4}{|c|}{ Batteries } \\
\hline \multicolumn{1}{|c|}{ Village } & Pairs of Batteries/month & $\underline{\text { L./mo. }}$ & $\underline{\text { US\$/mo. }}$ \\
\hline Danta Uno & 2.13 & 36.2 & 1.92 \\
\hline Nuevo Jutiapa & 2.31 & 42.0 & 2.22 \\
\hline Las Flores & 2.55 & 41.0 & 2.17 \\
\hline La Paz & 2.35 & 39.0 & 2.06 \\
\hline All & 2.34 & 39.6 & 2.09 \\
\hline
\end{tabular}

\begin{tabular}{|l|c|c|c|}
\hline \multicolumn{4}{|c|}{ Cell Phone } \\
\hline \multicolumn{1}{|c|}{ Village } & Days between recharge & $\underline{\text { L./mo. }}$ & $\underline{\text { US\$/mo. }}$ \\
\hline Nuevo Jutiapa & 4.12 & 24.0 & 1.27 \\
\hline Las Flores & 4.32 & 34.0 & 1.80 \\
\hline La Paz & 5.93 & 27.0 & 1.43 \\
\hline
\end{tabular}




\begin{tabular}{|l|l|l|l|}
\hline All & 4.79 & 28.3 & 1.50 \\
\hline
\end{tabular}

\begin{tabular}{|l|c|c|c|}
\hline \multicolumn{4}{|c|}{ Total Monthly Energy Costs } \\
\hline \multicolumn{1}{|c|}{ Village } & $\underline{\text { Mean }}$ & $\underline{\text { Median }}$ & $\underline{\text { US\$ }}$ \\
\hline Nuevo Jutiapa & L. 132 & 123.0 & 6.99 \\
\hline Las Flores & L. 139 & 116.0 & 7.36 \\
\hline La Paz & L. 129 & 103.0 & 6.83 \\
\hline All & L. 133 & 114.0 & 7.06 \\
\hline
\end{tabular}

\begin{tabular}{|l|c|c|c|}
\hline \multicolumn{3}{|c|}{ Approximate Monthly Income / Household } \\
\hline \multicolumn{1}{|c|}{ Village } & Mean & & US\$ \\
\hline Nuevo Jutiapa & L. 1,540 & & 81.50 \\
\hline Las Flores & L. 2,158 & & 114.21 \\
\hline La Paz & L. 1,443 & & 76.37 \\
\hline All & L. 1,714 & & 90.69 \\
\hline
\end{tabular}

\begin{tabular}{|l|c|c|c|}
\hline \multicolumn{4}{|c|}{ Household Population } \\
\hline Village & No. of Children & $\underline{\underline{\text { No. of }}}$ & \\
\hline Danta Uno & 2.58 & 2.04 & Total \\
\hline Nuevo Jutiapa & 3.45 & 2.41 & 5.79 \\
\hline Las Flores & 3.33 & 2.62 & 5.95 \\
\hline La Paz & 2.65 & 3.05 & 5.70 \\
\hline All & 3.00 & 2.53 & 5.58 \\
\hline
\end{tabular}


' Evan Mills, “The Specter of Fuel-Based Lighting,” Science, Vol. 308, May 27, 2005

ii Central Intelligence Agency, The World Factbook, Honduras, https://www.cia.gov/library/publications/the-worldfactbook/

iii DN Sikolia, "The Prevalence of acute respiratory infections and the associated risk factors: A Study of children under five years of age in Kibera Lindi Village, Nairobi, Kenya,” Japanese National Institute of Public Health, 51 (1): 200

iv A report from the US Embassy, Tegucigalpa, "Problems at State Electric Company Darken Honduran Energy and Fiscal Outlook,” November 2007.

v United Nations Publication, “The Secretary-General's Advisory Group on Energy and Climate Change (AGECC), Energy for a Sustainable Future,” Report and Recommendations, 28 April 2010, 7

${ }^{v i}$ Engineers with a Mission is the student organization arm of the 501(c)3 non-profit organization Global Appropriate Technology Ministries which seeks to promote engineers serving impoverished and marginalized peoples using culturally and technologically appropriate technologies. www.EngineersWithAMission.org

vii Bobby Brock, Michael Gallimore, Rhett Herron, "World of Light, Providing Lights to the World's Underprivileged" awarded the John Hoover Award in the Global Social Entrepreneurship Competition sponsored by the University of Washington Business School, for a business plan to provide electric lighting to urban residents of a large African slum using a micro-franchised business model.

viii http://www.designtechnologiesllc.com

ix Adam Harvey, Micro-Hydro Design Manual, A guide to small-scale water power schemes, (Warwickshire UK: Intermediate Technology Publications Ltd, 1993)

× Allen Inversin, Micro-Hydropower Sourcebook, A Practical Guide to Design and Implementation in Developing Countries (Arlington, VA: NCECA International Foundation, 1986)

${ }^{x i}$ Mills, "The Specter of Fuel-Based Lighting"

xii "Small Fortunes, Microcredit and the Future of Poverty", a film by BYU Broadcasting, 2005

xiii Jason Fairbourne, Stephen W. Gibson, W. Gibb Dyer, Microfranchising, Creating Wealth at the Bottom of the Pyramid (Glos, UK and Massachusetts, USA: Edward Elgar Publishing Limited, 2007), 33

xiv Paul Polak, Out of Poverty, What Works When Traditional Approaches Fail (San Francisco. CA: Berrett-Koehler Publishers, Inc., 2008)

${ }^{x v}$ Teodoro Sanches, Electricity Services in Remote Rural Communities, The Small Enterprise Model (Warwichshire UK: Intermediate Technology Publications Ltd., 2006)

${ }^{x v i}$ Fairbourne, Gibson, and Dyer, Microfranchising, Creating Wealth at the Bottom of the Pyramid, 29-31

xvii Nigel Smith, Motors as Generators for Micro-Hydro Power (Warwichshire UK: Intermediate Technology Development Group, 1994) 